\title{
Urgences
}

\section{Pour écrire que...}

\section{Gilbert Dupuis}

Numéro 15, octobre 1986

\section{Épigraphiques}

URI : https://id.erudit.org/iderudit/025353ar

DOI : https://doi.org/10.7202/025353ar

Aller au sommaire du numéro

\section{Éditeur(s)}

Urgences

\section{ISSN}

0226-9554 (imprimé)

1927-3924 (numérique)

Découvrir la revue

\section{Citer ce document}

Dupuis, G. (1986). Pour écrire que... Urgences, (15), 95-96.

https://doi.org/10.7202/025353ar

Ce document est protégé par la loi sur le droit d'auteur. L'utilisation des services d'Érudit (y compris la reproduction) est assujettie à sa politique d'utilisation que vous pouvez consulter en ligne.

https://apropos.erudit.org/fr/usagers/politique-dutilisation/
Cet article est diffusé et préservé par Érudit.

Érudit est un consortium interuniversitaire sans but lucratif composé de l'Université de Montréal, l'Université Laval et l'Université du Québec à Montréal. Il a pour mission la promotion et la valorisation de la recherche. https://www.erudit.org/fr/ 


\section{Gilbert Dupuis}

- Je me demande, dit le chef, quelle forme aurait une poire si elle poussait dans un pays où il n'y aurait pas de gravité.

Boris Vian: Les fourmis

Pour écrire que l'herbe était rouge, il faut songer à contester la couleur de l'herbe. Et pour contester ladite couleur, il faut être habité par l'idée que la couleur du monde est une variable - et non une donnée (pour emprunter au langage mathématique). Le monde est une équation à plusieurs inconnues. Le créateur - dont je veux parler - identifie plein de variables autour de lui. Le message des apparences, l'existence au premier degré ne le satisfont pas. Il sait sa vie plus riche que sa biographie. Le créateur a le sixième sens pour la cinquième dimension...

Comment qualifier mieux l'attitude - non la technique - du créateur? Je l'imagine en deux temps: (1) refus d'un ordre définitif des choses et (2) désir d'inventer l'ordre qu'il lui plairait de vivre. Le créateur se sent propriétaire - plus que locataire - du monde. Il n'accepte pas a priori les plans de la maison, ni la disposition des meubles. Il multiplie/enrichit ses réalités en en inventant d'autres qui combleront les manques des premières... Cette démarche du créateur se nourrit de l'insatisfaction du monde tel qu'il lui apparaît. Il note davantage ce qui manque que ce qui existe. C'est ce qu'on appelle avoir des visions. Le créateur voit ce qui va exister.

Créer c'est faire. Le premier sens de faire c'est réaliser hors de soi. Créer c'est changer une créature de monde. C'est tirer le désir du virtuel. Le créateur transforme des parties de son monde intérieur en un tout du monde sensible. L'oeuvre est une synthèse. Bien davantage qu'une analyse. L'artiste s'intéresse au particulier, le scientifique au général. L'homme de science observe un ensemble de phénomènes particuliers, puis il tire des conclusions générales (pour n'avoir plus à s'occuper des cas particuliers)... L'artiste se passionne pour l'exception, pour les cas limites, pour le singulier... L'oeuvre est une synthèse particulière d'éléments singuliers. L'oeuvre serait un raccourci éclairant!

Seul un mécanicien sait entendre un moteur, seul un menuisier prévoit bien le travail du bois, seul un pilote semble à l'aise dans la cabine de pilotage... Toutes ces personnes de métier connaissent bien leurs environnements respectifs. Ils tutoient les pistons, les bois, les 
manettes... Ils peuvent donc comprendre et maîtriser leur univers. Celui pour qui le monde est un ensemble de signes peut les utiliser pour s'adresser à lui dans ses propres termes. Les formes, la couleur, la fonction, l'ordre, le langage sont des signes du monde. Dès qu'on perçoit le monde comme un système de signes régi par toutes sortes de lois (physiques, sociales, politiques, etc.), dès qu'on voit le monde comme un texte, une peinture, une sculpture, comme une oeuvre inachevée, il y a désir de prendre la relève et - utilisant les signes du monde - de le compléter!

Pour le créateur, le monde est un langage et la communication n'a pas de fin... 